Journal of Jungian Scholarly Studies

Vol. 6, No. 4, 2010

\title{
Writing Nature with Darwin, Darwinism and Jung
}

Susan Rowland, Ph.D.

Pacifica Graduate Institute, CA

\section{Introduction}

"Ecocriticism" is a relatively recent flowering of critical study dedicated to understanding the relations between literature and the environment. Focused mainly on artistic works and cultural theory, the term is rarely applied to writers such as Charles Darwin (1809-1882) or C. G. Jung (1875-1961). On the one hand, such reticence is appropriate in keeping ecocriticism firstly for the study of imaginative writing about nature. Secondly, ecocriticism tries to find better ways of humans connecting to, or with, nature.

On the other hand, Darwin's theory of evolution was radical in reconceiving Homo sapiens as simply a human species among nonhuman species. Suggestively, C. G. Jung believed nonhuman nature to begin in the unconscious. Might these writers contribute to ecocritical theory? Alternatively, might an ecocritical perspective offer insights to their work? Both possibilities will be attempted here.

Furthermore, Darwin and Jung have been too little considered as nature writers. For, as recent research by Gillian Beer has shown, Darwin is forced by the nature of his material to become a speculative and mythical author (Beer 1983). Indeed, this paper will demonstrate that Darwin, in pivoting his ideas around the unknowable aspects of thousands of years of evolution, and Jung, not dissimilarly adhering to the unknown in the psyche, resorted to similar literary and artistic strategies. Both authors found that writing about nature and human nature demanded the arts of metaphor and myth. What follows from this coming together of revolutionary writers on the science of nature and the nature of the psyche is the basis of this study.

Therefore, this paper looks at three attempts to link nature and writing. First of all, Gillian Beer's Darwin's Plots does more than the author intended in showing the literary struggles innate to Charles Darwin's great work, On the Origin of Species (1859). In Beer's work we see that Darwin as a creative writer faced many problems similar to those C. G. Jung faced when he came to write about human nature. To clarify this fascinating overlap, I will look at the far newer coining of "literary Darwinism," an attempt at putting evolutionary theory into literary studies 
that is fatally flawed, for this newly minted literary criticism is neither effectively "literary" nor thoroughly "Darwinian".

\section{Plotting Darwin}

Gillian Beer's Darwin's Plots: Evolutionary Narrative in Darwin, George Eliot and Nineteenth-Century Fiction (1983), offers in its analysis of On the Origin of Species a remarkable exposition of the literary qualities that Darwin found vital to scientific writing. In the first place, it shows Darwin's growing awareness that discourse cannot be expunged from science (46). By discourse Beer means the way language is saturated with social, political and conventional expectations. For example, Darwin, who opposed slavery, was alert to the way the presentation of nature could be used to naturalize coercive human structures (50).

Discourse was a particular problem for Darwin because in describing evolution he was attempting to tell a different story about nature. Yet he had to use the language and structures inherited from traditional theological accounts of how the natural world came to be. Darwin was attempting to orient the story of nature to his key idea of natural selection as the way in which species mutate and transform. Such a concept was directly opposed to the preceding discourse of natural theology.

What was ultimately so successful about On the Origin of Species was that it outlined a system of understanding nature without any external authority generating, designing or ordaining the way things are. Darwin wrote God out of his picture of nature. Evolution as Darwin presented it was a totally self-sufficient system. This does not mean that it could be written about totally. Darwin's problems with language are partly those of science in general, encountering the biases built into the way words work, and partly those generated by the monumental ambition of his task (47-49).

In the first place, language is anthropocentric, having emerged and evolved so as to function in the human social world; whereas Darwin not only eliminates God, he removes humans from the center of his theory. Secondly, language assumes agency. We habitually create meanings around actions done by someone or something. Darwin was trying to get away from the notion that someone or something initiated evolutionary transformation. The generic problem of language and agency proves to be part of Darwin's specific difficulty in writing against the grain of his inherited discourse of natural theology. Here Darwin resorts to an ingenious solution: evicting the traditional paradigm of the Christian God, he invokes the older myth of sacred Nature, the Earth Mother.

All these difficulties with language add up to something very important to any writing about nature. Evolutionary science theorizes that humans are not the center of meaning, while language presupposes that humans are the location of understanding. In this sense, language does not correspond to material reality. 


\section{Rowland}

Darwin had a major story to tell. What he did not have was a medium adapted to tell it. It was not just that most of the theory of evolution was not provable within the paradigms of science that he inherited. Science in the nineteenth century still drew upon principles laid down by Francis Bacon's Novum Organum (1620), and as extended by John Stuart Mill, in his A System of Logic (1843).

These guidelines for science not only assumed the existence of empirical phenomena that could be subjected to repeated experiments. They also called for inductive reasoning in order to establish "laws." Inductive reasoning requires being confident about multiple instances of a natural event before being able to ascertain a causal sequence. Effectively, scientific method, based upon the separation of observing mind from nature, insisted upon by Descartes and the spectator mind (see above), had a built in supposition of material causation, and was designed to investigate the nature of the present. How could the scientific method be used to describe a world of thousands of years ago?

Using traditional scientific methods, Darwin could not prove that natural selection had occurred in the distant past. He could not experiment on dinosaurs. Nor could he be confident that he could cite multiple instances of an ancient event sufficient to use inductive reasoning to propose a definitive material cause. As Beer shows, Darwin is writing history. Here is a major work of science in which a human lifetime is an irrelevant span of time to the major argument. What Darwin can do is examine the diversity and profusion of species existing now and posit an anterior narrative. What is so powerful in Beer's analysis is how she shows that Darwin needs the resources of fiction and the artistic qualities of writing in order to write his new story of how nature evolves.

However, before looking at fiction and myth in Darwin, we should consider one other significant gap in his writing. Darwin, not unlike Jung, accepts that there is something unknowable about the workings of nature. As Beer says:

Darwin displays, categorizes and argues, but does not expect to contain the workings of the world in his mind, or ever fully to understand them. He believed that he had discovered the mechanism of evolution but he did not expect to encompass the whole process. Indeed his theory was necessarily hypothetical rather than traditionally inductive... (46).

Darwin never doubts the world is real. But he does doubt our categories for understanding it and indeed questions, while he shares, the categorizing zeal of human beings (xxx).

The mechanism of evolution was natural selection: nature selected, not God. It was a term formulated to pivot the argument away from the preceding view of 
nature as designed through theology. The other motif of Origin was the topos of diversification. His nature is creative because it is by mutation, not an adherence to previous forms. Whereas contemporaries were shocked by its emphasis on natural selection, Beer shows how Darwin's text now looks more like ecology. He finds in nature an "inextricable web of affinities" (Darwin 415; qtd. in Beer 18).

Moreover, his stress on the creativity of profusion in nature does not stop with his argument. Sense metaphor and analogy are crucial to his writing strategy; they embody plural possibilities in his text. The creativity of profusion is also in the writing of Origin. Darwin utilizes the 'gap' and the possibility of other meanings inherent in metaphor. As Beer puts it, the resulting thesis on evolution is "essentially multivalent... renounc[ing] a Descartian clarity, or univocality" (6).

A further somewhat surprising resource in the writing of Origins as science is its dependence upon myth. In order to explicitly do away with a father God organizing nature from outside the natural order itself, Darwin has recourse to the ancestral mother. Nature is a creature for very ancient myth, in which the earth itself is sacred and generative. Beer shows Darwin's earth mother myth inhering in the "maternal principle" of natural selection (64). Darwin's uses natural selection as maternal because he wants it to appear benign and nurturing.

Yet it would be wrong to imply that Origins is a reversion to prescientific ideas about nature. On the contrary, many of the metaphors and analogies are tuned to revising rather than ignoring the previous great book of nature, the Bible. Beer demonstrates how Darwin does not get rid of myth for some other kind of writing, called "science." In fact, he replaces the Biblical myth of nature with his own new creation myth (107).

Evolutionary theory implied a new [creation] myth of the past: instead of the garden at the beginning, there was the sea and the swamp. Instead of man, emptiness --- or the empire of molluscs. (Beer 118).

Beer establishes Darwin as a Romantic materialist. She means that he has faith in nature as a creative, nurturing force, as well as fearing its "emptiness;" yet he sees no need for explanations outside the material natural order (93). He is also, she explains, a creative writer, if not, ultimately, a fictional one (95). In addition to metaphor, analogy and myth, what is fundamental to Origins is narrative.

Perhaps it is time to propose an analogy between Darwin's writing and Jung's writing. Both thinkers struggle with the task of writing about nature. For Darwin, writing about nonhuman nature reveals the inadequacies of language as a window onto the world. It is not. Rather nature has to be related to in a web of language that uses the imagination to mythically invoke a never-to-be-fully comprehended whole. Jung, on the other hand, is primarily concerned with psychic nature. However, it is a psychic nature that extends into the non-human. How do his 


\section{Rowland}

similar problems with representation suggest a way forward for ecocriticism? I will show that Jung's preoccupation with that which cannot be directly represented offers some daring and radical insights for ecocriticism.

\section{Jung and the Problem of Writing On the Nature of the Psyche}

Jung has two key notions. Everything stems from a creative in part unknowable unconscious, and secondly, that the unconscious human psyche has a psychoid penetration of matter. In this section I am going to continue to avoid what is neat and coherent in Jung's theory in favor of examining further his struggle to write about psychic nature. By comparing what Jung does for psychic nature with what Darwin did for evolutionary nature, I hope to begin to show some of the ecocritical benefits of a Jungian framework. Using a Jungian approach to psyche and nature, I suggest, will expose and refine the question of human consciousness.

In an essay called "On the Nature of the Psyche" (CW8: 1946/54), Jung attempted to show the scientific derivation of his theory. His problem is that what he wants to write about is the unconscious. By definition, the unconscious cannot be written about because it is not witnessed. Like Darwin, Jung speaks of unknown laws that he is unable to deduce from the previously established laws of nature (par. 375).

Unsurprisingly, Jung resorts to metaphor and analogy. A crucial metaphor is that of light to suggest both knowledge and consciousness. From dim apprehensions in the early part of the essay, light becomes a means of differentiating the energy of one of Jung's major ideas, that of archetypes. An archetype is an inherited structuring principle of image and meaning. Jung uses an analogy of the light spectrum to suggest that the red instinctual pole of the archetype is where it folds into the body and its psychoid energy. The violet pole of the light spectrum signifies where the archetype seems to have escaped bodily incarnation altogether and become spirit.

Also like Darwin, Jung draws on earlier literature to drag some of its representation capacity toward his unknown realm. Where Darwin rewrote mythical motifs of the Bible, Jung delved into the texts of alchemy for evidence of a consciousness more in touch with the psychic unknown. We see here that, like Darwin, metaphor becomes substantiated: light is not representing consciousness metaphorically; it is consciousness.

Since consciousness has always been described in terms derived from the behaviour of light, it is...not too much to assume that these multiple luminosities correspond to tiny conscious phenomena. (CW8, par. 396) 
Jung is here referring to works of symbolism seeking for something called "the light of nature" or lumen naturae ( $C W 8$, par. 389). His essay frames these obscure historical works of alchemy as a parallel investigation into the creative unconscious using the discourses of another era. Just as Darwin invoked the earth mother myth to portray natural selection as non-human yet not without humanity (maternal, etc), so Jung uses alchemical symbolism to convert his light of argument metaphor (dim apprehensions) to enact the light of consciousness.

Indeed, Jung is explicit on the role of poetic language as superior in expressive qualities than rational or logical terms (CW8, par. 409). Here is a particularly evocative use of nature as metaphor.

The moment one forms an idea of a thing... One has taken possession of it, and it has become an inalienable piece of property, like a slain creature of the wild that can no longer run away. (CW8, par. 356)

Jung is not addressing nonhuman nature; rather, he is looking at the nature of the psyche and how it can be captured in writing. For to write about the psyche is to fall into a trap. Only the psyche itself, meaning all the properties of the human mind, conscious and unconscious, can reflect upon the psyche. There is no standpoint outside the psyche from which to view it with scientific detachment. If there is a nature of the psyche, then it is one in which we are always enmeshed.

However, the metaphor of the slain creature of the wild says more than just that psychologists stalk the psyche from within its environs. Like all metaphors it is a comparison that exposes a gap while proffering a likeness between two or more aspects. Here the various members of the metaphor are the idea of a thing, an inalienable piece of property, and a slain creature of the wild. The metaphor spans the meaning-making about psyche (idea), culture (property) and nature (creature). To seize upon a definitive idea about the psyche is to grasp it as a property. Such a greedy maneuver is equivalent to killing a wild animal that can no longer escape.

What is striking about this metaphor is the link it makes between control of meaning and despoliation of the natural world. In this it represents a profound ecocritical insight, suggesting a real potential for Jung in ecocriticism. To raid the psyche in the form of claiming an idea is secure and fully known, to claim ownership of a psychic idea, is to both slaughter the animal (idea) and believe that it represents some psychic truth. To imagine that one knows something absolutely about psychic nature is to stake a claim in the Land of the Dead.

Remembering the slain creature is to recall Jung's sense that perfectly defined ideas about the psyche not only miss its living qualities, but can in themselves drain its vitality. A few lines later he is even more trenchant. Using a concept can, in itself, distort psychic reality ( $C W 8$, par. 356). This is because concepts are icons of rational language. They belong to the ego. To Jung, they therefore have limited 


\section{Rowland}

applicability to the most important aspect of the psyche, the creative and in part unknowable unconscious.

In effect, to Jung the ego is culture; its rational thinking and logical concepts belong to the human world. But that leaves a lot of the human psyche to be colonized by the "other," non-human nature. We may call to wild creatures and speak to them, as long as we do not kill them with our sterile concepts. The rational ego is culture; it is environed by wild nature that produces our dreams and intuitions, and is marked by the tracks of other creatures than ourselves.

Nevertheless, Jung admits that we cannot do without rational and conceptual thinking. What he seeks to do is return conceptual abstractions to their roots in a more protean psychic nature. What is native to the psyche is creative fantasy and images produced in dreams then transmuted into art. Hence psychic imagery and psychic meaning are identical, because the flowering of the unconscious in human creativity is more innate, more "true" than any ego-centric rational construction. When it comes to psychic nature, Jung wants it to speak for itself and regards interpretation as unnecessary (CW8, par. 402).

So, in addition to dream images, Jung here values such arcane visual symbolism as the tail-eating serpent, the uroboros, used by alchemists, as evidence of unconscious qualities (CW8, par. 416). The uroboros expresses a secret of nature; it does not describe it. Jung suggests that the symbol indicates the circulation of energy within psychic nature. As there is a cycle of energy in the natural world, so Jung sees a similar fertilizing cycle of energy exchange between conscious and unconscious. Moreover, the two cycles are interlinked. Human unconscious entities, which he called archetypes, are part of nature (CW8, par. 412).

Like Darwin, Jung uses the term "nature" universally. As Darwin placed humans firmly within nature, in natural selection, so Jung designates the unconscious as the natural part of the human being, connected to nature via the psychoid (CW8, par. 417).

Finally, on the question of the difficulty of writing about psychic nature, Jung has recourse to analogy in order to posit a theory. If concepts and rational thinking are less authentically psychic in nature than creative fantasy, then theory cannot be assumed to be unproblematically valid. In fact, Jung has exactly the same problem as Darwin. For Darwin, language was anthropocentric, but his theory of evolution was not; it centered on "emptiness" and "molluscs," as Beer put it. Similarly, for Jung theory is rational ego-centered, yet the truth of the psyche is unconsciouscentered. Suggestive for future ecocritical arguments, Jung placed the natural part of humans as the center of his psychology. Yet the unconscious as the true source of the psyche cannot be coherently theorized. 
So Jung has recourse to analogies of the net, the model and the pivot to put forward his theory. He says that his psychology is merely a model because it is simply a framework or a perspective on the psyche (CW8, par. 381). He describes himself immersed in his research, discovering it to be a "net of reflections" that lead beyond science and into the humanities (CW8, par. 421). Meditating upon the paradoxical experience of using the psyche to investigate the psyche, he describes it as a pivot that shifts the entire order of the world ( $C W 8$, par. 423).

For Jung, the world is a cosmos of natural energy. Only the human psyche is capable of generating consciousness to such an extent that the natural order is put at risk. As he points out, all of human learning is a specifically honed form of consciousness. In his own time, physics, a product of the psyche like everything else in culture, can "kill seventy-eight thousand persons at one blow" (CW8, par. 421).

It seems that both Darwin and Jung can contribute ideas and method to ecocriticism. For they demonstrate the necessity of artistic strategies of writing to treat of the nonhuman. In particular, they show the consequence of changing priorities over the role of human beings as the center of meaning. In particular, Jung suggests new ways of figuring the boundary between nature and culture as within the human imagination. The truly groundbreaking quality of these writers is made even more visible by contrasting their work with the new critical edifice of literary Darwinism. For here is an approach to the arts that seeks to eradicate the unknowable qualities of humans and/in nature.

\section{Literary Darwinism: A Science of the Arts?}

By looking at the topic of so-called "literary Darwinism," I want to show how far removed from Darwin it actually is. It is Jung who is far more the heir to Darwin in writing about what cannot be physically witnessed.

In, Literary Darwinism: Evolution, Human Nature and Literature (2004), Joseph Carroll substantiates the groundbreaking program of his earlier work, Evolution and Literary Theory (1995). Both texts propose a critical practice built around terms avoided by Darwin and Jung, of causality and the treating of one form of knowledge as unproblematic source for all others.

Indeed, while conceding that all knowledge is partial, even hypothetical (18), Carroll insists that "Darwinian evolutionary theory has established itself as the matrix for all the life sciences" (15). His keyword is "adaptation," which is the means by which nature, including human nature, concedes to natural selection. For Carroll, literature is derived in a "simple causal sequence" (xii).

Adaptionists would affirm the following two causal propositions: (1) the mind has evolved through an adaptive process of natural selection; and (2) the adapted mind produces literature. (Carroll xii) 


\section{Rowland}

In such a way literature can be comfortably positioned as a significant field, yet one under the territorial government of science. Carroll argues for a "scientifically valid understanding of literature" (29). Literary Darwinism is in this way part a greater project, that of unifying all knowledge. In this case, the unity is not a net or a web as intimated by Jung, and arguably Darwin, in Beer's reading. Rather it is a reduction of the arts and humanities to propositions that tuck them under the wing of a particularly hardline strain of evolutionary social studies, as I shall show. Carroll cites the scientist E.O. Wilson who, in Consilience: The Unity of Knowledge (1998), argued that all aspects of human nature, including its tendency to produce art, can be understood as part of a chain of causal sequences (Carroll 70).

Here nature, operating by causality, is susceptible to rational investigation. Wilson coined "consilience" to describe the coming together of the humanities and the sciences under the explanatory paradigm of Darwinism. Yet consilience cannot be regarded as a unity of enquiry so much as a reorganization of disciplines of knowledge according to Darwinian principles that miss the originator's sense of incompleteness and literary experimentation in his great works. For example, Wilson and Carroll define their science of nature as exploring a world of interconnected mechanisms (Carroll 39). On the other hand, the notion of a mechanistic is also disputed today, as I shall show.

Other problems emerge when this reductive Darwinism is applied to literature. Whereas some Darwinians consider literature as a human adaptation for passing on information, giving models of behavior for the future or game-plan possibilities, others link art to sexual reproduction. Here literature is generated as a form of sexual display, signaling superior capacities to future mates (Carroll xx). Wilson's addition to this rather basic collection of biological motivations is that literature has evolved as part of adaptation because it builds the superior brain power of the human animal (Carroll 69).

Natural selection has found the high cognitive abilities of humans advantageous. To maintain these, however, it was necessary to detach mental capabilities from actual environmental conditions. Literature is part of what fills the gap between what the environment demands of humans and our ability to imagine and conceive. Here is the opportunity for literary Darwinians to escape the most deterministic prescriptions of literature. Certainly the theory regards success in reproducing as "an ultimate causal force;" yet it may seek fulfillment in indirect or proximate causes (Carroll 9-10).

Unfortunately, Carroll gives as one principle of his Darwinian analysis the formula that characters and setting in the realist novel correlate with the scientific notion of an organism adapting, or not, to its environment. Such a prescription 
presupposes a number of contentious points, not considered by Carroll. For example, it suggests that the nineteenth century realist novel is the highest form of literature because it most closely resembles Darwinian norms. It thereby exposes how this mode of literary criticism wipes away any consideration of the social and ideological shaping of artistic genres.

Discourse is not allowed to intervene in literary Darwinism, and indeed, Carroll presents his ideas explicitly as an alternative to either formalism or textualism (1517). By "formalism" he means concentration on genre as source of literary meaning. By "textualism" he denounces the way poststructuralist literary theory regards the text as so independent of any reality outside itself as to come to replace it. Bound up in these approaches are those derived from Marxism that regard literature as the result of interconnecting forces of power and money. Literary Darwinism, Carroll believes, offers the clean and superior epistemological alternative of scientific causality.

Carroll also assumes that language is an unproblematic window onto the world. Both the belief in evolution as "a mechanical process of adaptation," and that literary works may be translucent to these interactions, depend upon the notion of language providing a stable system of meaning in which words correlate with material reality. Darwin and Jung discovered that words do not work like that. They needed to use metaphor and analogy as substantial terms in order to write of a realm in which humans are not the origin of meaning.

Carroll seems to be both aware and unaware of the problem of language in a paradigm that downplays human centrality. Firstly, he is aware insofar as he insists that literary Darwinism returns to a universal human nature as the source of literary values. This human nature is Darwinist in that it is biologically rather than culturally conceived. Thought, motivation and the production of literature are confined to the human sphere (160).

On the other hand, Carroll shows no sign of noticing that both he and Darwin have recourse to the Earth Mother myth in order to posit the all-encompassing paradigm. When Carroll calls Darwinism the "matrix" of the arts and sciences, he is transferring the Earth Mother goddess of nature from Darwin's vision of nature to the nurturing and originary powers of Darwin's texts (ibid.: 15). This is certainly a kind of textualism, for its grants mythical powers to Darwin's words that he himself was loath to claim. Even if Darwin's works are purely transparent to the scientific truth, Carroll's mythical imaginings grant supernatural fertility to a body of texts. Such a strategy sits ill with literary Darwinism, which is supposed to rest content with a world of mechanical causality.

Therefore, I want to end this article with a survey of the as yet underdeveloped potential of Jung for ecological literary criticism. Essentially, Jung models three important ecocritical strategies: he reinvents the assumed divisions between nature 


\section{Rowland}

and culture; he shows ways of communicating with the nonhuman; and finally, he parallels human and natural creativity.

\section{Jung Reinvents Nature/Culture Boundaries}

Whereas Freudian/Lacanian tradition pushes toward a binary understanding of nature versus culture, in which nature inheres in the bodily embrace of the mother which must be repressed, Jung offers a model of the psyche in which there are productive exchanges between ego and unconscious. Indeed, since the Jungian unconscious is the source of being, and is embedded in the body and in nature, his mode of subjectivity; e.g., individuation, is dedicated to loosening the apparent dichotomy between nature and culture.

In effect, the Jungian psyche is dedicated to finding authenticity of being by shifting from the binary system of an over-rationalized modernity to one in which the so-called "laws of nature" include unconscious archetypes. In many ways Jung follows in the footsteps of Darwin here. Whereas Darwin showed humanity to have kinship with molluscs, to be a type of animal, Jung also wants to re-place humanity in the natural order. Both thinkers work by incorporating the unknowable into their writing. Moreover, both of them end up with an idea of language as participant in the natural order, rather than external to it.

\section{Jung Models Communication with Nature}

Although the Jungian psyche and his idea of language are rooted in nature, Jung, like Darwin, was wary about claiming authority for his theory by naturalizing it. In The Collected Works volume 9i: Aion, he argued that his own characteristic notions were simply another version of previous discourses of the imagination, such as alchemy, Gnosticism and astrology. He knew that culture and history shaped psychic signifying.

However, with a psyche that penetrates nature and psychic nature, his work provides models for approaching nature today. First of all, we notice a foundational structure in his core theory: the dialogue between monotheism and animism. The notion of archetypes is an animistic structure because it liberates a psyche of many voices, is embedded in the unknowable, and has sources for generating meaning. This ancient architecture of the soul is partnered with Jung's privileging of one archetype and call it the self. Here is monotheism, meaning gathered up into oneness and unity, imposed upon a bedrock of animism more rooted in the variety of nature.

The archetypes of the psyche may be projected onto nonhuman nature; or, as I have been arguing, may be continuous with nonhuman nature in the psychoid 
aspect of archetypes. The other way to see the animistic psyche as nature's voices is to remember the new science of the field, and the wisdom of Gaia, or geophysiology, in which all of nature is entangled. So Jung provides a model of human psychic incorporation in nature. It might be possible to argue that the human unconscious is, in some sense, a consciousness for nature. Yet, it is here necessary to remember ecocriticism's ethical commitment to the nonhuman other can be met by Jung's assertion of the ethical and meaningful priority of the unconscious other.

So the Jungian psyche models the superimposition of monotheism on animistic connections to nature and can, perhaps, model its undoing. As a second way of envisioning nature ecocritically, Jung revalues myth as a foundation of knowledge. Myth, we recall, has proved indispensable to Darwin, even literary Darwinism, and certainly to non-Western, shamanic understandings of nature. Now I will mention another of Jung's useful contribution to ecocritical cultures.

\section{Jung on Creativity and Nature in the Arts}

Again, since Jung's unconscious psyche is distinguished by creativity and is partly unknowable, this also describes his vision of nature. Hence, the imagination and all its works are psychic texts imbued with nature and body.

Of course, Jung notes that not all works of culture resonate with the depths of the archetypal psyche. He categorizes images, which includes words in literature, into two types: signs and symbols. To Jung, a sign relates to a known thing or idea. It exemplifies what Lacan calls the Symbolic Order, and Jung calls, cultural consciousness: the known order of society. Conversely, symbols are redolent of the deep unconscious. Indeed, because we all inherit the same sorts of archetypes, Jung called it the "collective unconscious." Symbols bring intimations from the unconscious, from nature, and from the body. Yet symbols are not innocent of culture. Since even inspired art is filtered through the ego, the ego's history will affect the art.

Another key ingredient that Jung's theories of art take from his psychology is the notion of teleology. Individuation is goal-oriented because it is going somewhere in its pursuit of ever greater union with the self. Jung never specified the end point of his telos. At times he suggested that it was a spiritual preparation for death. What matters here is that he suggested that works of art deeply embodied in the creative and partly unknowable psyche could be teleological for the culture. After all, his theory of individuation through unconscious compensation of ego bias, is here enacted as a cultural level. A society's blindness summons forth a compensating art from the depths of its roots in unconscious nature.

To conclude, I suggest that, first of all, the fascinating parallels between Darwin and Jung as writers about (human) nature are a revelation that barriers between science and the arts are porous. Both authors remind us that science is also a discourse that seeks to absorb a mysterious reality into the enigmatic world of 


\section{Rowland}

signs. Secondly, both these writers reinstate myth and metaphor as vital and literary means of expression when contemplating the non-human. Reading both for their literary methods is oriented here to looking at these texts through the lens of ecocriticism. In decentering human rationality, they reveal something of their quest to represent the non-human in an ecocritical framework.

Such groundwork is then intensified with Jung's imaginative amplification of natural metaphors. His "slain creature" is a vivid realization of how language can kill. Hence he offers a stark and exciting picture of the psyche as divided from nature by culture. Modernity has cultivated the ego and fenced it off from the imaginative and unconscious psyche by techniques such as rationality and logical concepts. Jung sought to re-root the fantasy-starved ego back into its native land in the psyche's wilderness of dream and the "other."

Here Jung as a writer explores the psyche ecologically. His experimental treatments of representing the unconscious and exploiting marginalized discourses make him ecocritical. Moreover, his speculative leaps in figuring human creativity with/in the nonhuman, and in being receptive to nonhuman attempts to communicate with, and rebalance, our societies--- such daring feats of imagination may inspire an ecocriticism for the future.

\section{Works Cited}

Beer, G. Darwin's Plots: Evolutionary Narrative in Darwin, George Eliot and Nineteenth-Century Fiction. Cambridge: Cambridge UP, 1983. Print.

Carroll, J. Literary Darwinism: Evolution, Human Nature and Literature. London and New York: Routledge, 2004. Print.

Darwin, C. On the Origin of Species. New York: Random House, 1979. Print.

Hayles N. K. The Cosmic Web: Scientific Field Models \& Literary Strategies in the $20^{\text {th }}$ Century. Ithaca: Cornell UP, 1984. Print.

Jung, C. G. The Collected Works of C. G. Jung. Ed. Sir Herbert Read et al. Trans. R. F. C. Hull. Bollingen Series 10. Princeton: Princeton UP, 1953-79. 20 vols. Print

Kuhn,T. The Structure of Scientific Revolutions. Chicago: Chicago UP. 1968. Print. 